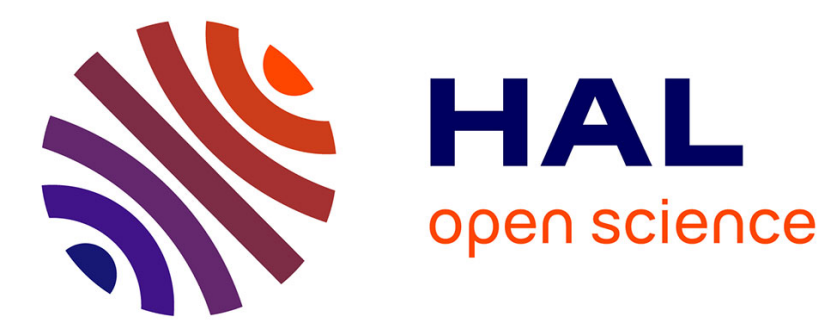

\title{
Towards a Semiotic-Based Approach to the Design of Therapeutic Digital Games
}

Paula Souza, Kamila Hora Rodrigues, Franco Eusébio Garcia, Vânia Almeida Neris

\section{- To cite this version:}

Paula Souza, Kamila Hora Rodrigues, Franco Eusébio Garcia, Vânia Almeida Neris. Towards a Semiotic-Based Approach to the Design of Therapeutic Digital Games. 18th International Conference on Informatics and Semiotics in Organisations (ICISO), Jul 2018, Reading, United Kingdom. pp.53-62, 10.1007/978-3-319-94541-5_6. hal-01920718

\section{HAL Id: hal-01920718 https://hal.inria.fr/hal-01920718}

Submitted on 13 Nov 2018

HAL is a multi-disciplinary open access archive for the deposit and dissemination of scientific research documents, whether they are published or not. The documents may come from teaching and research institutions in France or abroad, or from public or private research centers.
L'archive ouverte pluridisciplinaire HAL, est destinée au dépôt et à la diffusion de documents scientifiques de niveau recherche, publiés ou non, émanant des établissements d'enseignement et de recherche français ou étrangers, des laboratoires publics ou privés.

\section{(c)(1)}

Distributed under a Creative Commons Attribution| 4.0 International License 


\title{
Towards a Semiotic-based Approach to the Design of Therapeutic Digital Games
}

\author{
Paula Maia de Souza, Kamila Rios da Hora Rodrigues, Franco Eusébio \\ Garcia and Vânia Paula de Almeida Neris \\ Department of Computing - Federal University of São Carlos - Brazil \\ paula.souza@ufscar.br, kamila.rios@gmail.com \\ \{franco.garcia, vania\}@dc.ufscar.br
}

\begin{abstract}
Healthcare professionals may employ therapeutic games as playful activities to promote rehabilitation for their patients. However, despite the importance, currently the literature does not provide multidisciplinary approaches to support designing these games. To overcome this scenario, we propose a semiotic-based approach to aid stakeholders with different backgrounds on designing therapeutic digital games. The approach results from a study of the literature and reports of the experience of a multidisciplinary team on the creation of therapeutic games. It explores Participatory Design and Organizational Semiotics methods and artifacts to promote the Problem Clarification, Interaction Modeling, Design Materialization, and Evaluation as fundamental design practices of effective solutions. The approach was evaluated to design new therapeutic games and the results suggest that it helps the team on identifying therapeutic objectives and reaching them.
\end{abstract}

Keywords: Therapeutic Games, Participatory Design, Organizational Semiotics, Evaluation, Games for Health, Health.

\section{Introduction}

The market for games is expanding to new areas including education, training and health. For the latter, therapeutic games may promote awareness and provide treatment for patients in efficient and potentially cheaper ways [4]. However, due to their goal -healthcare --, these games require careful development. In special, for their success, it is essential to foster collaborative efforts from multiple stakeholders, including domain specialists (such as healthcare professionals), computer professionals, artists, and, at times, family, government, and patients themselves. Moreover, semantic, pragmatic and social issues should also be considered. The nature of therapeutic systems demands a sociotechnical approach to its design and development [11].

Given the multiple variables involved to ensure success and quality of a therapeutic digital game, we believe a structured process, which recognizes the technical system as part of a whole information system, could assist designing, implementing, evaluating and easing the adoption of these games. However, as far as we know, there is no similar approach in literature. Thus, this paper presents a first step towards this structured process, describing an approach to create therapeutic games, based on Participatory Design (PD) [15] and Organizational Semiotics (OS) [8, 17]. OS is a discipline that explores 
the use of signs and their effects on social practices. In the OS approach, an organization and its information system are considered as a social system in which human behaviors are organized by a system of norms. An organization is understood as an information system in which people use signs for communication towards purposeful and coordinated actions. In this sense, any technological artifact, e.g. a software application, is embedded in a formal system that, by its turn, exists in the context of an informal system $[8,17]$.

For evaluation, the process was used in a new context and the results suggest it helps the team on identifying therapeutic objectives and supports to reach them.

\section{Related Work}

Mader et al. [9] affirm that, even though therapeutic games might be very promising, they are still very complex to design and develop. Their reasoning is that therapeutic games present four main design challenges: creating a motivational game, exchanging information, therapeutic gameplay and defining the process. To ease the process, they proposed a model called Player/Game/Therapy (P/G/T). As an analytical tool, the main idea of $\mathrm{P} / \mathrm{G} / \mathrm{T}$ is to analyze each aspect of a therapeutic game independently and the relationships between pairs of them (i.e. player-game, therapy-player and therapygame). In the model, Player relates to patient, who assumes the role of player in a game. The authors emphasize that it is important to gather general information about the patient, including her/his situation and skills to play, as this data are needed to design a game that is playable and enjoyable for the patient. The Game serves to define game basics (genre, platform and devices), brief description of its story, gameplay and world. Finally, Therapy describes the therapy elements which should be present in the game - including therapeutic goal, protocol and context.

In addition, Mader et al. [9] states that a limitation of their method is that patients are studied but not involved, and health specialists have the role of providing knowledge and validating the design. Thus, we believe that a PD approach could enrich the design and improve the overall effectiveness of the resulting game.

Cheng, Putnam and Guo [3] conducted a survey, through detailed interviews, with 11 game designers. The author's intent was to understand how designers judge and perceive the success of games for health projects, how they think and act on the challenges, how they acquired domain knowledge and rated their games, and what tools they used to support their work. They found that most therapeutic game designers value and practice user-centered design principles (e.g. user focus, user testing from the start), and tended to place emphasis on initial user engagement and user search. Most of the designers mentioned using interviews with target players as being one of the first steps to approach a therapeutic game project. Participants also said they relied on iterative prototyping processes and game tests to refine their understanding of the domain and target users.

Cheng, Putnam and Guo [3] report that incorporating serious content into an engaging gaming experience is an important but difficult aspect. In addition, maintaining 
successful stakeholder collaboration is also important, but challenging in serious gaming projects for health. They also report that user-centered efforts do not always help with some of the prominent challenges, such as communicating with subject matter experts and conducting enduring experiences for players. These findings indicate that more research is needed to help support designers of therapeutic digital games to overcome the challenges discussed by the respondents.

In this sense, we started working to provide a design approach to aid computer and healthcare professionals in creating therapeutic digital games co-developed by different stakeholders and supported by a sociotechnical view.

\section{Methodology to Formalize the Approach}

Aiming to acquire relevant requirements, our methodology employed a literature review and an interview with researchers who created a therapeutic game in an ad-hoc way. These requirements supported us to create and formalize an initial approach, which we evaluated and improved by applying it to a new therapeutic context.

In the review of the literature, we searched for papers that reported the design of therapeutic digital games in the Association for Computing Machinery (ACM), Institute of Electrical and Electronics Engineers (IEEE), and Scopus databases. Although several studies described the use or the creation of therapeutic games, most results did not report using any specific methodology for designing therapeutic games. Section 2 summarized the works considered relevant. Among the lessons learned from these works, it is possible to highlight: the importance of involving stakeholders in all stages of therapeutic game design, and the importance of considering relationships between player, game and therapy.

In addition to the literature review, a non-structured interview (carried out as a playful activity using cards, questions and answers) was carried out with researchers from the computing and health domains, who developed the game "Jogar Também Faz Bem!" (Play makes good as well!) to support depression treatment. The game won the best demonstration award at the XV Brazilian Symposium on Human Factors in Computing Systems [12]. We interviewed the project coordinator, three $\mathrm{PhD}$ students (two from the healthcare area, one from the computing), a master's student (computing area) and four undergraduate students (three from the computing area, one from healthcare). The aim was to collect lessons learned from their experience on developing a therapeutic game. These results are described in Section 4.

From the literature review and the study of the "Jogar Também Faz Bem!" game, it was possible to propose a four stage approach to the design of digital therapeutic games. For evaluation, the approach was instantiated in another therapeutic context. 


\section{$4 \quad$ Analyzing the Design of a Therapeutic Game for the Depression}

Our non-structured interview with the "Jogar Também Faz Bem!" researchers started mapping the origin of the game. According to the researchers, an employee of a public hospital which provided treatment to patients with depression contact the research group from a nearby city university aiming to acquire software to support the rehabilitation of their patients. At the time, a literature search performed by the researchers indicated a lack of formal methodologies and approaches regarding digital therapeutic games development, especially aimed for mental health problems.

Therefore, those researchers decided to adopt Baranauskas and Bonacin's view for a design process [1] and instantiate then to the therapeutic context [11]. Baranauskas and Bonacin explore a combination of $\mathrm{PD}[15,10]$ and $\mathrm{OS}[8,17]$ practices, considering design as a social process of expressing meaning, communicating intentions and constructing knowledge, to be carried iteratively and interactively by designers and a group of stakeholders in a participatory style. A complete discussion on why Baranauskas and Bonacin's view was adopted can be found in [11].

Figure 1 shows the Semiotic Onion, an OS artifact, instantiated by Neris and Rodrigues [11] to attend the therapeutic information system.

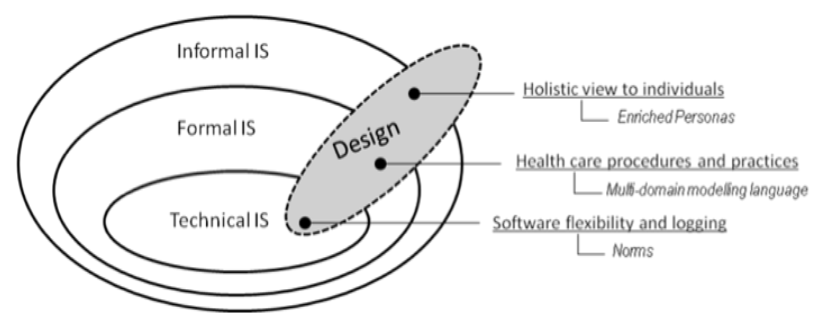

Fig. 1. Semiotic Onion considering signs to Therapeutic Systems [11].

According Neris and Rodrigues [11], in the therapeutic system scenario, the particularities of each patient should consider a holistic view, including his/her personal information, family and close people history, healthcare professionals, and academic and demographic studies. In the formal layer, it is important to identify the health procedures and protocols which also underline the therapeutic objectives. Finally, in technical level system flexibility and data logging aspects need to be addressed. Flexible features can be implemented considering cognitive and physical aspects of the patients that are important to be respected during the interaction.

Aiming to map patients' medical profiles and needs with design requirements for the game, the researchers used OS artifacts with the Personas technique proposed by Cooper [5]. The result of the use of artifacts from OS and Personas was called Personas Enrichment Process (described in section 5) [14]. The enrichment was carried out in a participatory way: hospital professionals contributed to propose, improve, and evaluate the created personas. 
In order to identify suitable mechanics and genre for the game, the researchers employed a participatory practice exploring the PICTIVE technique [10]. In this new activity, the group of computer professionals provided images for healthcare professionals with illustrations of characters and scenarios of digital games. These professionals analyzed the images and were asked to choose the ones which better matched their patients' interests and could better suit the therapeutic practice.

Considering the multidisciplinary nature of game creation, the researchers found it could be useful to foster communication and collaboration among stakeholders with different backgrounds. To benefit from domain knowledge of every stakeholder, they defined an Interaction Modeling Language for Therapeutic Applications [6]. The language adopted graphical symbols to promote collaborative design by computer, health, and artists professionals alike, trying to reduce communication and technical barriers required. Moreover, given the therapeutic nature of the game, the researchers considered it was important to allow healthcare professionals to track the progress of patients over several sessions. Thus, they introduced collecting (logging) interaction data of patients' interactions within the game, and evaluation activities to test their cognitive abilities.

Initial functional prototypes of the game to patients and hospital professionals were delivered. Healthcare professionals could generate reports summarizing the collected data to examine if their patients improved over the playing sessions. Besides the builtin game evaluation, playtest with patients also started featuring the Self-Assessment Manikin (SAM) [2] evaluation as a post-section questionnaire for self-assessment of a patient's emotional state. The feedback collected after a playtest session was positive.

Next, a healthcare student of the researchers' group analyzed the game in a new context, using it as an entertainment resource for elderly patients on hemodialysis at a specialized hospital. Despite the difficulties of application, due to the hemodialysis process, the patients appreciated the game. However, for researchers, this was an opportunity to improve the game's accessibility. For this, they incorporated accessibility and usability improvements in the game, including: spoken instructions, transcription in Brazilian Sign Language (LIBRAS), and alternative input schemes (mouse, keyboard, controller).

\section{$5 \quad$ An Approach to the Design of Therapeutic Games}

With the results from Section 2 and Section 4, we started defining an approach to support designing therapeutic applications. The approach was divided into four stages (see Fig. 2): 1) Design Problem Clarification, 2) Interaction Modeling, 3) Design Materialization, and 4) Evaluation.

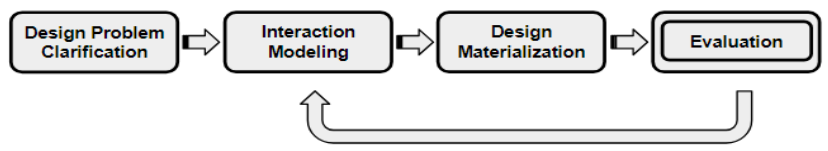

Fig. 2. Stages of the Design Approach. 
Design Problem Clarification aims to understand the use context of the game. Therapeutic games are in a multidisciplinary context; thus, it is useful to explore PD practices to benefit from the knowledge of all stakeholders. In special, healthcare professionals knowledge is essential to discover and understand therapeutic requirements. Stakeholders must work together to determine suitable ways to address these requirements into gameplay. A possible approach to achieve that is exploring the following steps: brainstorming, Personas Enrichment Process, elicitation of therapeutic objectives, elicitation of requirements, and PICTIVE (see Fig. 3).

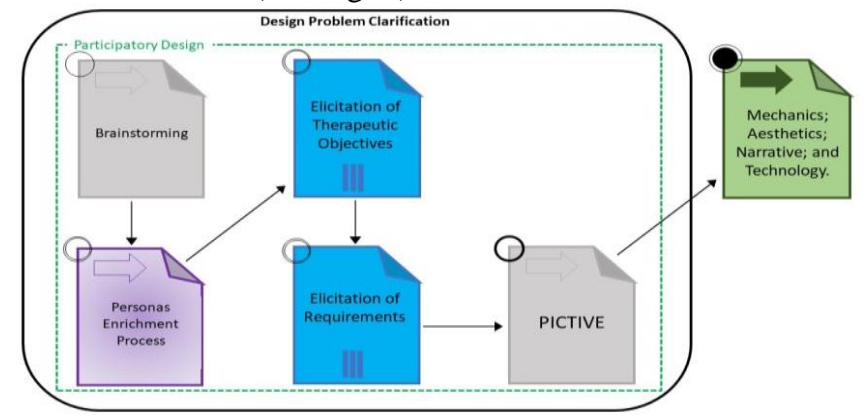

Fig. 3. Design Problem Clarification.

The application of the brainstorming technique is the event that initiates the flow of this stage, followed by the Personas Enrichment Process (see Fig. 4) [14].

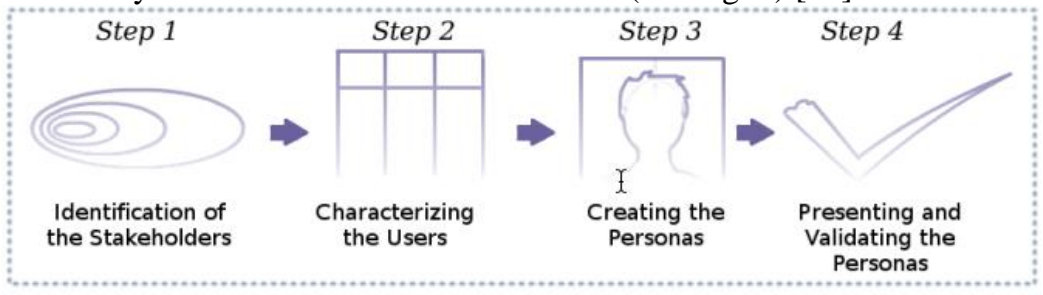

Fig. 4. Personas Enrichment Process [14].

In Step 1 of the Enrichment Process, a multidisciplinary team uses the Stakeholder Analysis Chart (see Fig. 5a) $[14,16]$ to identify people and institutions related to the system. Step 2 employs the Evaluation Frame (see Fig. 5b) [14, 16] added to other artifacts, to identify clinical profiles of patients, medical procedures, patients' relationship with other interested parties, and problems involved in creating the application alongside possible solutions.

In Step 3, the fictional characters idealized by healthcare professionals become Personas representing real people. Researchers with computer background should aggregate information from the literature (public health data) to detail the individuals with relevant information. Afterwards, healthcare professionals should evaluate the correctness of the Personas, approving them provided they are suitable (Step 4) [14]. 
After the validation of the created persons, the therapeutic objectives and the requirements that the game must attend must be raised. It is understood by therapeutic objective, the objective of the game in treating a certain pathology and in how to help in the improvement of this pathology.

For the identification of the dynamics and genre of the game it is advisable to apply the PICTIVE technique [10], this being the last event in the flow of the clarification stage. As a result of this step we have the mechanics, aesthetics, narrative, technology. The techniques, artifacts and processes suggested for this step were described in Section 4.

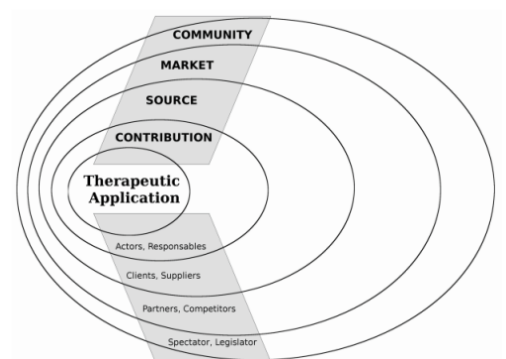

Fig. 5a. Stakeholder Analysis Chart [14, 16]

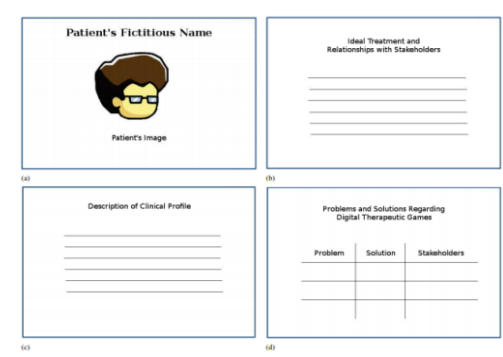

Fig. 5b. Evaluation Frame and other artifacts $[14,16]$.

The next stage is Interaction Modeling. Considering that therapeutic applications involve a multidisciplinary team, all stakeholders can benefit from an easy-to-understand language -- preferably requiring minimal computer-specific knowledge. For this reason, it is advisable to use a Domain Specific Modeling Language (DSML) for the design, such as the Interaction Modeling Language [6].

Next comes the stage Design Materialization, consisting of sketching, prototyping and/or defining an initial version of the application based on the chosen DSML. For this stage, exploring PD and prototyping techniques and tools can be useful: screen sketches and prototypes allow drafting the game look and feel before implementing high fidelity prototypes, fostering participation of stakeholders without computer backgrounds and promoting faster design iterations. To enable more people to use the system, it is necessary to consider aspects of universality for the design in a therapeutic context. For instance, health conditions may hinder movement or restrict the use of an $\mathrm{arm} / \mathrm{hand}$ (as in the case of patients undergoing dialysis).

Finally, due to the critical nature of the therapeutic domain, any proposed solution should be evaluated by healthcare and computer science professionals -- this is the goal of the Evaluation phase. Evaluation should, thus, happen at all stages of development: from the initial modeling and prototypes to the final product. Evaluation should consider gameplay, accessibility, emotional aspects and therapeutic purposes of the game. 


\section{Approach Evaluation}

To evaluate the approach described in Section 5, a group of professionals from another Brazilian public university carried out an extension project in partnership with a public hospital specialized in treatment of childhood cancer. The project aimed to design a digital therapeutic game to support the rehabilitation of children under treatment for cancer [13].

In Stage 1 from this approach, the professionals conducted meetings with a hospital's therapist and used participatory practices to discover the domain and the target audience, to clarify requirements for the game, and to identify the gender and characteristics desirable for the interaction with the game to be developed for children in treatment.

The professionals instantiated the Personas Enrichment Process [14] and used its artifacts to identify stakeholders. By using the Stakeholder Analysis Chart $[14,16]$ they identified the patients, the family, healthcare professionals and researchers, as well as the hospital and the government, as the main stakeholders in the development of the therapeutic game for the cancer treatment [13]. By applying the Evaluation Frame artifact $[14,16]$, they identified the clinical profile of the children being treated for cancer in that hospital (from newborns to people with 35 years old, with Leukemia, Osteosarcoma or Central Nervous System (CNS) tumor), medical procedures used in them (e.g. chemotherapy and radiation therapy), the patient's relationship with other interested parties (including healthcare professionals and the very protective caregivers), problems involved in creating and using the game (e.g. side effects in the use of 3D format, etc.), and possible solutions to these problems (e.g. use of 2D format). From these participatory practices, three main Personas were identified [13]. The collected data was enriched with information from the Literature regarding childhood cancer, including INCA (Brazil's National Cancer Institute) registration data about child and adolescent cancer in Brazil [7]. An occupational therapist of the specialized hospital evaluated and validated the resulting Personas [13].

According to the researchers, Stage 1 allowed to identify that each of the three Personas created has different needs, which imply in requirements regarding the flexibility of the game. Some possibilities for the game include features to improve self-esteem (e.g. in pre-teen patients who are in an age of discovering their body) and promote positivism, clarifying the treatment and entertaining children and caregivers. The instantiation of Stage 1 also helped researchers to identify the importance of illustrating in the game, in playful ways, changes that occur in the children's body due to the treatment [13].

In Stage 2, the modeling language was used to model scenarios and interactions for supporting treatment cancer in the therapeutic game. This stage, however, has not yet (at the time of writing) been completed its cycle and, thus, has not yet been evaluated by hospital professionals. Nevertheless, according the researchers [13], part of scenarios foreseen for the game already was modeled. The scenarios illustrate, for instance, the materialization of some peculiar aspects and flexibility pointed out by professionals, among them, the flexibility of parts of the game to meet different user profiles and different therapeutic objectives. 
In Stage 3, members of the computer science team created prototypes of the scenarios already modeled. One of these prototypes represent game screen with the hospital room where the healthcare professional (from different areas) explains patient care and caregivers from her/his perspective of her/his area of practice (e.g. Occupational Therapy, Medicine, Nutrition, etc.). The prototypes should validate suitability of modeled interaction and allow hospital professionals to evaluate game creation modeling and flow. However, the researchers point out that, as in Stage 2, the evaluation with the professionals of the artifacts generated in Stage 3 of the approach has not yet occurred, because the modeling of the scenarios is still under development.

About the design approach, the evaluation group emphasize that, following the first steps, it was possible to involve healthcare professionals in the creation of a game that also supports their activities as therapists. According to the researchers, in addition to involving the stakeholders in the process, the artifacts used for collecting requirements provide more reliable information to the domain in study and may allow more adhesion to the proposed therapeutic application.

\section{Conclusion and Future Works}

To turn digital therapeutic games into tools supporting professional healthcare practices, we need to support the design of effective solutions with methods and techniques. Ideally, a semiotic-based approach to the design of therapeutic games aiming to guide involved stakeholders into game creation could, potentially, help the creation of more effective solutions.

Combining results from the literature with studies carried out by a research group that had developed a therapeutic game to aid depression treatment, this paper presents initial steps towards an approach to support the design of therapeutic games. The approach describes a four stages process to guide the development.

An instantiation of the approach was conducted in a different therapeutic context to evaluate it. Preliminary results pointed by the evaluators suggest positive aspects in the involvement of healthcare professionals as co-producers of the solution in question. Domain-specific features, and therefore, peculiar therapeutic aspects, should not, and cannot, be conceived entirely by computer professionals if aiming for effective therapeutic solutions. Rather, it is important to allow as many stakeholders as possible to contribute their designs. For this, PD may be useful, as it promotes co-creation of the therapeutic solution -- which is characterized as serious by the Literature and has the responsibility of helping in therapeutic treatments.

Although the preliminary results of the validation conducted are positive, the design approach must be applied in new contexts in order to further evaluate and improve the process.

Acknowledges. The authors would like to thank the healthcare professionals and administrators of HEM-Marília and HA-Barretos, and healthcare and computer science researchers from UEMG - Frutal and UFSCar for their effective collaboration. CAPES for financial support. 


\section{References}

1. Baranauskas, M. C. C.; Bonacin, R.: Design-indicating through signs, Design Issues, vol.24, no.3, pp.30-45, Jun. 2008. [Online]. Available: http://dx.doi.org/10.1162/desi.2008.24.3.30

2. Bradley, M. M., Lang, P. J.: Measuring Emotion: The Self-Assessment Manikin and the Semantic Differential. Journal of Behavior Therapy and Experimental Psychiatry 25, 1 (1994), 49-59. DOI: http://dx.doi.org/10.1016/0005-7916(94)90063-9

3. Cheng, J., Putnam, C., Guo, J.: "Always a Tall Order": Values and Practices of Professional Game Designers of Serious Games for Health. In Proceedings of the Annual SIGCHI Annual Symposium on Computer-Human Interaction in Play, (CHI PLAY '16), (2016) 16-19, Austin, TX, USA

4. Cheung, M.: Therapeutic Games And Guided Imagery: Tools for Mental Health And School Professionals Working With Children, Adolescents, And Their Families. Lyceum Books (2016)

5. Cooper, A.: The Inmates Are Running the Asylum: Why High Tech Products Drive Us Crazy and How to Restore the Sanity (2nd edition ed.). Pearson Higher Education (2004)

6. Garcia, F. E., Rodrigues, K. R. H., Neris, V. P. A.: Uma Linguagem de Modelagem de Interação Para Aplicações Terapêuticas. In Simpósio Brasileiro Sobre Fatores Humanos Em Sistemas Computacionais. São Paulo (2016)

7. INCA - Instituto Nacional de Câncer (Brasil):: Coordenação de Prevenção e Vigilância de Câncer. Câncer Na Criança e No Adolescente No Brasil. Instituto Nacional de Câncer, Rio de Janeiro (2008)

8. Liu, K.: Semiotics in Information Systems Engineering. Cambridge University Press, Cambridge; New York (2000)

9. Mader, S., Natkin, S., Levieux, G.: How to Analyse Therapeutic Games: The Player / Game / Therapy Model. In Entertainment Computing - ICEC 2012, Marc Herrlich, Rainer Malaka, and Maic Masuch (Eds.). Number 7522 in Lecture Notes in Computer Science. Springer Berlin Heidelberg, (2012) 193-206

10. Muller, M. J.: PICTIVE - an Exploration in Participatory Design. In Proceedings of the SIGCHI Conference on Human Factors in Computing Systems (CHI '91). ACM, New York, NY, USA, (1991) 225-231. DOI: http://dx.doi.org/10.1145/108844.108896

11. Neris, V. P. A., Rodrigues, K. R. H.: Design of Therapeutic Information Systems as Indicating Through Signs. In Socially Aware Organisations and Technologies. Impact and Challenges (IFIP Advances in Information and Communication Technology). Springer, Cham, (2016) 203-208. DOI: http://dx.doi.org/10.1007/978-3-319-42102-5_23

12. Nishikawa, D., Novak, L., Azevedo, M., Branco, P. C., Olivi, R., Brandão, R., Garcia, F. E., Neris, V. P. A.: Se Cuidar, Cuidar de Algo, Se Divertir e Aprender Fazem Bem! Demonstração de Um Jogo Para Apoiar o Tratamento Da Depressão. In Anais Do XV Simpósio Brasileiro Sobre Fatores Humanos Em Sistemas Computacionais. São Paulo (2016)

13. Rodrigues, K. R. H., Conrado, D. B. F., Neris, V. P. A.: Lessons Learned in Designing a Digital Therapeutic Game to Support the Treatment and Well-Being of Children with Cancer. In: Human-Computer Interaction (HCII 2018). Lecture Notes in Computer Science. Springer, Berlin, Heidelberg, to be published (2018)

14. Rodrigues, K., Garcia, F. E., Bocanegra, L., Gonçalves, V., Carvalho, V., Neris, V. P. A.: Personas-Driven Design for Mental Health Therapeutic Applications. SBC Journal on Interactive Systems 6, 1 (2015), 18-34 
15. Schuler, D., Namioka, A.: Participatory Design: Perspectives on Systems Design. L. Erlbaum Associates, Hillsdale, N.J (1993)

16. Stamper, R. K.: Analysing the Cultural Impact of a System, in International Journal of Information Management (1988), 8, p. 107-122

17. Stamper, R. K.: Language and Computer in Organized Behaviour. In Linguistic Instruments in Knowledge Engineering, R.P. Riet and R. A. Meersman (Eds.). Elsevier Science, (1992) $143-163$ 